\title{
A UNIVERSIDADE E A FORMAÇÃO PROFISSIONAL DOS DOCENTES: NOVOS QUESTIONAMENTOS
}

\author{
Claude Lessard
}

RESUMO: Este texto propõe uma análise da situação atual da formação profissional para o ensino e suas relaçôes com a universidade a partir da potencialização de uma vontade de maior eficácia por parte do Estado. Ele identifica três desafios: 1) a colocação em tensão de abordagens plurais do desenvolvimento profissional dos docentes e da melhoria das escolas, 2) os modos de gerenciar a obrigação de resultados em formação, por parte dos professores, e, por trás desses dois primeiros pontos, 3) as relaçóes com a "ciência" e a "pesquisa" no contexto do retorno em força da "ciência dura". Com relação a esses desafios, uma universidade tem mais autonomia que um Instituto de Educação (École normale) e pode, ao se reivindicar da "esquerda do parlamento da ciência” (Kant), afastar certos perigos. Se a universidade não conseguir colocar em tensão fecunda abordagens plurais da melhoria da prática e das escolas, ter uma resposta sofisticada à obrigação de resultados e nem desenvolver nos docentes uma relação crítica com a ciência, quem conseguirá?

Palavras-chave: Formação profissional para o ensino. Universidade. Obrigação de resultados. Eficácia e relação crítica com a ciência.

\section{UNIVERSITY AND THE PROFESSIONAL TRAINING} OF TEACHERS: NEW QUESTIONINGS

ABSTRACT: With regard to the professional training of teachers in university settings, this paper presents an analysis of the present situation based on the rise of the State's insistence on greater effective-

* Ph.D. Education Theory, OISE (University of Toronto, Canadá); professor titular do Departamento de Administração e dos Fundamentos da Educação, titular da cátedra de pesquisa do Canadá sobre os ofícios da educação, Faculdade de Ciências da Educação, Universidade de Montreal, Quebec (Canadá). E-mail: claude.lessard@umontreal.ca

Tradução de Alain François, com revisão técnica de Ivany Pino.

Disponível em <http://www.cedes.unicamp.br> 
A universidade e a formação profissional dos docentes: novos questionamentos

ness. It identifies three issues: 1) the necessary tensions between plural approaches to teacher development and school improvement; 2) the ways of dealing with forms of obligation of results in teacher training, and 3) the definition of "science" and "research" in the context of the return to prominence of "hard sciences". It argues that a university has more autonomy than a normal school and can hold itself aloof from certain perils. If university is unable of generating fruitful tensions between plural approaches to teacher development and school improvement; of sophisticatedly responding to the obligation of results; and of developing a critical relationship to science in teachers, who will be?

Key words: Professional training in teaching. University. Obligation of results. Effectiveness and critical relationship to science.

Políticas estatais: entre o New Public Management (Nova Gestão Pública) e a profissionalização

$\mathcal{N}$

o contexto econômico e político atual, o ensino superior ocupa um lugar importante. Há incontestavelmente um fundo de verdade no discurso dos reitores e diretores de universidades sobre a centralidade do ensino superior no âmbito movediço da economia do saber e da globalização. A qualidade da mão-de-obra e a produção de um saber de ponta nos diferentes setores de atividade são desafios maiores para os Estados e as grandes regiōes do mundo. Daí a massificação do ensino superior e esse enorme impulso da escolarização para o alto. Com relação a uma ou duas geraçôes atrás, um diploma superior talvez não garanta tanto uma carreira prestigiosa, bem remunerada e segura, mas, atualmente, não ter um traz conseqüências infinitamente mais negativas. De fato, os Estados compreenderam que sua economia não tem muita coisa a oferecer a pessoas pouco escolarizadas: logo, para permanecer competitivo, é preciso investir numa mão-deobra altamente qualificada e capaz de aprender coisas novas ao longo de sua vida profissional.

O fato de o ensino superior aparecer como central, hoje em dia, faz com que não se possa deixar seu desenvolvimento sem planejamento de conjunto, sob o único controle da corporação universitária. Dito de outro modo, o preço da importância aumentada do ensino superior é uma maior intervenção do Estado e mais globalmente dos grandes atores sociais, a qual se traduz pela contratualização, por uma presta- 
ção de contas mais apertada e por uma pressão mais forte do lado da eficácia e da eficiência. $\mathrm{Na}$ América do Norte, isso toma a forma de avanços da New Public Management, que submete universidades, faculdades, departamentos e programas a medidas de rendimento, de eficiência e de eficácia. Isso afeta tanto os setores acadêmicos como os profissionais, talvez muito mais estes últimos, embora, em contrapartida, isso lhes traga benefícios incontestáveis.

Essa evolução repercute sobre as ordens de ensino inferiores. Por um lado, o ensino superior precisa de um fluxo contínuo de estudantes bem formados e aptos a empreenderem e concluírem estudos superiores longos e exigentes. Por outro, os Estados entenderam que os custos sociais, econômicos e políticos da subescolarização ou de uma escolarização inadequada e de má qualidade são altos demais para que não se procure atrair, formar e reter no ensino uma mão-de-obra de qualidade e melhorar as escolas e sua eficácia. Daí o desenvolvimento de políticas neste sentido.

Em suma, essa exigência de uma mão-de-obra docente de melhor qualidade é claramente e cada vez mais um assunto de Estado que, pelo viés de políticas explicitamente voltadas para este objetivo, tenta

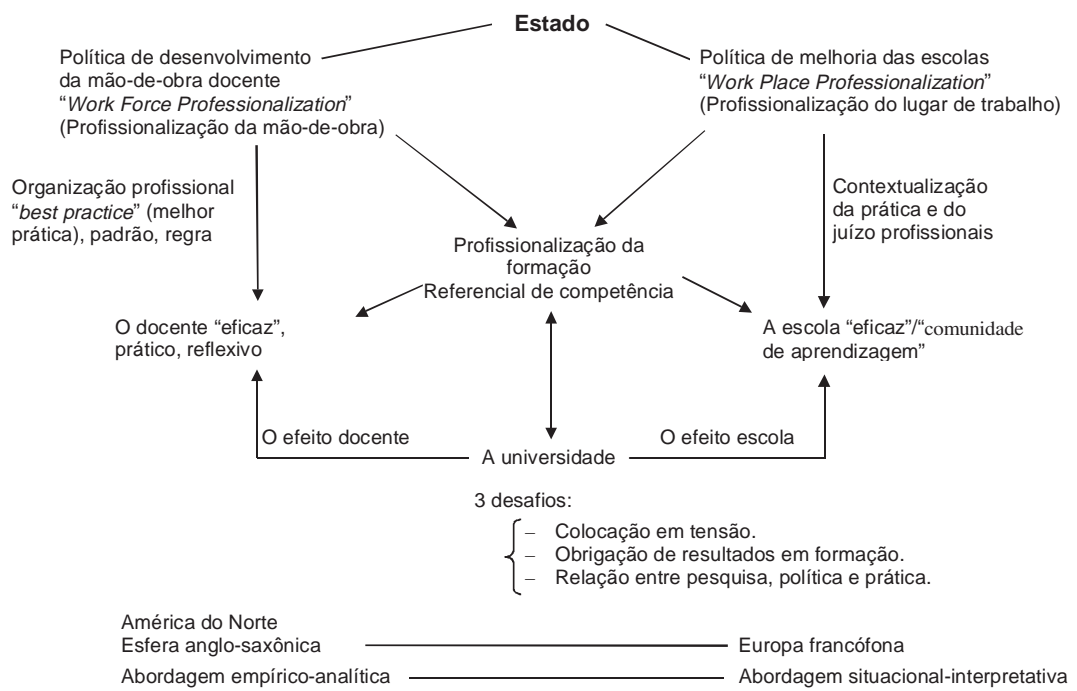

Educ. Soc., Campinas, vol. 27, n. 94, p. 201-227, jan./abr. 2006

Disponível em <http://www.cedes.unicamp.br> 
A universidade e a formação profissional dos docentes: novos questionamentos

coordenar o conjunto dos atores do campo do ensino, garantir a coerência e a sinergia de suas ações e inseri-los no âmbito mais global das políticas educativas focadas na economia do saber, na globalização da concorrência e na ética da responsabilização e do desempenho. Essa política de Estado procura não apenas vincular melhor, mas, se possível, alinhar os universos da formação inicial e do desenvolvimento profissional com as orientações de políticas educativas para a educação básica, por um lado, e as do ensino superior, pelo outro.

Recentemente, Grimmett et al. (2005) propôs distinguir o que chama de profissionalização da mão-de-obra docente ("work force professionalization") e a profissionalização do contexto de trabalho ("work place professionalization"). Isso remete à institucionalização, variável segundo os contextos nacionais, de duas políticas do Estado, uma de desenvolvimento da mão-de-obra docente, inspirada numa ideologia profissional, e uma de melhoria das escolas, caracterizada por diversos graus de descentralização, novos modos de regulação e uma prestação de contas inspirada por uma preocupação de eficácia.

Enquanto objeto de política estatal, a profissionalização da mãode-obra docente diz respeito ao conjunto das legislações, regulamentações e ações voltadas para a implementação de um sistema relativamente integrado de ação profissional que abrange e vincula de um modo que tende a ser sistemático:

1) uma formação superior, "universitarizada" e, sobretudo no mundo anglo-saxão, assumida e controlada por unidades de ciências da educação;

2) a contratualização ou o credenciamento pelo Estado ou por uma instância profissional reconhecida dos programas e das instituições que oferecem formação, assim como de escolas e docentes que participam da formação (em processos de profissionalização);

3) em função de um referencial de competências explícito;

4) ele próprio apoiado em e legitimado por uma base de conhecimentos que incorpore os resultados capitalizados da pesquisa;

5) um sistema de regulamentações que articule as exigências da qualificação profissional, o acesso ao emprego, a inserção profissional e a titulação; 
6) no mundo anglo-saxão, a instauração de uma corporação, de uma ordem profissional, ou de uma instância profissional representativa dos docentes;

7) uma forma de inspeção e de avaliação da competência profissional;

8) uma formação continua que tende a ser vinculada a reformas do ensino e/ou ao conceito de desenvolvimento profissional.

Poder-se-ia também chamar esses desenvolvimentos de institucionalização da profissionalização do ensino. Na América do Norte, essa institucionalização é movida pelo Estado e seu aparelho administrativo; ela atribui um lugar importante à instituição universitária (que vê nisto uma ampliação para o ensino primário e secundário de estruturas já muito pregnantes nas profissóes estabelecidas). Segundo a hoje famosa análise de Labaree (1992), ela corresponde aos interesses categoriais dos formadores universitários. Pode-se representá-la como um conjunto que supervisiona, regulamentando e dominando uma prática que o Estado deseja tornar mais eficaz.

Essa institucionalização não deixa de gerar tensões e conflitos. Se a idéia de uma formação superior parece necessária, sua importância, seus conteúdos e, sobretudo, seu controle são sempre objetos de debates; embora a idéia de recorrer à pesquisa e à ciência seja consenso, de que pesquisa e de que ciência se está falando? Apesar de, idealmente, regras elevadas de qualificação e de titulação, assim como dispositivos funcionais de inserção profissional, parecerem necessários, limitações da realidade forçam, às vezes, os empregadores a infringirem significativamente essas normas e regras; além do mais, uma antiga cultura de ofício continua impondo aos jovens docentes as condições de exercício mais difíceis. No mundo anglo-saxão, se em teoria uma forma de autogoverno profissional pareça válida, muita gente não deixa de se indagar se, na realidade, essas instâncias diversamente chamadas não seriam o braço do Estado para melhor controlar os docentes; o mesmo vale para a avaliação dos docentes, cujas finalidades, modalidades e conseqüências estão longe de ser unanimidade. Em suma, os avanços da institucionalização de uma política de mão-de-obra docente marcam acordos e acomodaçóes mais ou menos temporários entre os atores envolvidos.

O recente relatório da OCDE (Organisation for Economic Co-operation and Development), "Teachers matter: attracting, developing and 
A universidade e a formação profissional dos docentes: novos questionamentos

retaining effective teachers" (Assunto de professores: atrair, desenvolver e reter professores eficazes - 2005), é um belo exemplo desse interesse do Estado pela profissionalização da mão-de-obra docente. $\mathrm{Na}$ esteira de trabalhos recentes de Eurydice (2002a, b e 2003) sobre a profissão docente na Europa, e daqueles sobre a formação inicial e o desenvolvimento profissional dos docentes (OCDE, 1998), sobre os docentes para a escola de amanhã (OCDE; UNESCO, 2001) e dos trabalhos do CERI sobre a escola de amanhã (OCDE, 2001), a OCDE, com a colaboração de 25 Estados membros ou regiōes destes, estudou as políticas dos países colaboradores a respeito do conjunto ou de uma ou outra das dimensôes de uma política de mão-de-obra docente, a saber: o recrutamento e a seleção, a formação inicial e contínua, a inserção, e a retenção e seus fatores (que incluem a avaliação do ensino e o reconhecimento da excelência). $\mathrm{O}$ fato de 25 dos 30 países membros da OCDE terem se voluntariado para esse estudo é revelador da importância política da qualidade da mão-de-obra docente. $\mathrm{O}$ discurso que legitima essa vontade de ver os Estados assumirem um papel estratégico na profissionalização da mão-de-obra docente é hoje conhecido:

Todos os países buscam aperfeiçoar a qualidade de seus estabelecimentos escolares para melhor atender a expectativas sociais e econômicas cada vez mais elevadas. Recurso mais significativo e precioso no âmbito dos estabelecimentos escolares, o corpo docente está no cerne dos esforços visando a melhorar o ensino. A melhoria da eficácia e da eqüidade do ensino passa em grande parte pela capacidade de fazer com que indivíduos competentes desejem ensinar, que seu ensino seja de alta qualidade e que todos os alunos tenham acesso a um ensino de alta qualidade. (OCDE, 2005, p. 2)

Esse discurso se apóia em pesquisas que avaliam o efeito docente sobre as aquisições dos alunos. De fato, segundo a OCDE, essa pesquisa permite tirar três grandes conclusões: 1) As variações das aquisições dos alunos devem-se "essencialmente" à sua bagagem quando ingressam na escola - suas capacidades e atitudes assim como seu meio familiar e social. Entretanto, é difícil, para os tomadores de decisões, agir sobre esses fatores, pelo menos em curto prazo; 2) entre as variáveis sobre as quais se pode agir, as que dizem respeito aos docentes e ao ensino exercem a principal influência nas aquisições dos alunos: "a qualidade do docente" é a única variável escolar de peso que influencia os resultados dos alunos em geral; 3) os indicadores da qualidade dos docentes são 
sujeitos a controvérsia e difíceis de se medir, sobretudo quando se quer ir além do diploma e da experiência.

O relatório final, síntese dos 25 estudos de casos, ressalta a importância de uma política nacional de profissionalização da mão-deobra e fornece um quadro e um conjunto de orientaçôes para essa política. As dez orientações observadas nos estudos de casos e propostas pela OCDE para o conjunto dos países, na esfera da formação dos docentes, são uma boa ilustração disso:

1) desenvolver perfis da profissão docente para adaptar a formaçáo e o desempenho dos docentes às necessidades das escolas;

2) considerar o aperfeiçoamento do docente como um contínuo;

3) flexibilizar mais a formação dos docentes;

4) melhorar a seleção e o recrutamento em formação dos professores;

5) modificar o equilíbrio da formação;

6) melhorar a formação em meio escolar;

7) credenciar os programas de formação;

8) certificar os novos docentes;

9) reforçar os programas de inserção profissional;

10) integrar o desenvolvimento profissional ao longo da carreira.

Ressaltamos que o título do documento usa o adjetivo "effective" (eficaz) para descrever a qualidade buscada nos docentes, adjetivo que revela uma preocupação de desempenho bastante generalizada.

Como que para demonstrar o valor agregado deste nível de profissionalização, Linda Darling-Hammond (2000) analisou as políticas dos diferentes estados americanos a propósito dos docentes. Ela constatou que, onde esforços sérios e integrados foram feitos no sentido de uma política da mão-de-obra docente, os indicadores de desempenho dos alunos do primário e do secundário estavam em alta e superiores aos dos estados que investiram menos em sua mão-de-obra docente.

Logo, o Estado pressiona os formadores de professores para que produzam uma mão-de-obra docente eficaz e com bom desempenho. 
A universidade e a formação profissional dos docentes: novos questionamentos

Para o Estado, a profissionalização apenas tem sentido se garantir maior eficácia de ensino. Ela não é um fim em si, mas, antes, o instrumento de uma política. Logo, a obrigação de resultados, já presente nos outros níveis de ensino, desponta no horizonte da formação dos docentes. Isso coloca mais uma vez a pergunta do que é um docente eficaz.

Em contrapartida, ao longo das últimas décadas, políticas de melhoria das escolas e de sua eficácia foram implantadas em vários estados. Elas combinam elementos de descentralização, novos modos de regulação e de prestação de contas e uma preocupação em institucionalizar um papel ampliado para os docentes e em introduzir flexibilidade e adaptabilidade local. A prestação de contas pode se revestir de diversas formas: em vários países, ela passa pela classificação das escolas em decorrência do êxito dos alunos em testes padronizados, pela medição do efeito escola e do efeito docente e pelo cumprimento de quantitativos previamente acordados entre a escola e a instância superior. Os novos modos de regulação podem incorporar a livre escolha dos pais, a concorrência entre estabelecimentos, uma "gerencialização" (managérialisation) da administração e várias formas de contratualização. Nesse movimento de intensificação de uma forma de obrigação de resultados, surge, pelo menos em teoria, mais margem de manobra no plano da organização e dos recursos... Mas só em teoria, pois, onde se buscou responsabilizar as escolas pelo êxito de seus alunos, também se centralizaram os programas de ensino e a avaliação das aprendizagens, levando os docentes a alinharem suas práticas a esses dois elementos estruturantes.

Se a preocupação com a melhoria das escolas possa tomar essa via, típica do New Public Management, ela também pode tomar a via da profissionalização do contexto de trabalho. Esta é alimentada por diversas abordagens mais ou menos novas, como as das escolas eficazes, das comunidades de prática, da organização aprendiz ou inteligente, da melhoria da escola (school improvement), da mudança emergente e das estratégias de gestão da mudança de tipo bottom-up (de baixo para cima), as quais convergem todas para um melhor conhecimento e o desenvolvimento profissional de um sujeito individual e coletivo às voltas com a complexidade das situações reais de trabalho; elas lançam mão de diversas estratégias de capacitação (empowerment e capacity-building) e de metodologias e ferramentas de análise do trabalho, das situaçōes ou da atividade. Elas compartilham uma preocupação em construir com os próprios sujeitos um novo ofício e reconhecer suas vozes 
(teachers' voice). Aqui, o objeto de preocupação são as condiçôes locais da organização e da cultura do trabalho, que contribuem para desenvolver uma ou mais "profissionalidades" adaptadas e eficazes.

Todos esses cenários revelam uma forte comunidade de pensamento acerca das idéias seguintes: o ensino não pode evoluir sem a participação plena e inteira dos docentes; estes têm conhecimentos, crenças, projetos que se defrontam com um contexto de trabalho e situaçôes singulares; para se adaptarem às realidades, antigas e novas, incorporadas nas situações escolares cotidianas, os docentes são levados a desenvolver suas práticas e a considerá-las como hipóteses de trabalho, sobre as quais diversas formas de reflexividade podem e devem se exercer. E é na partilha com os colegas e os outros atores (especificamente pais, alunos e o staff escolar) que as "profissionalidades" vão se dotar de coerência e consistência, harmonizar-se e adquirir um certo coeficiente de eficácia.

Existem, portanto, políticas de Estado que dizem respeito tanto ao desenvolvimento da mão-de-obra docente como ao contexto de trabalho. Elas não são necessariamente contraditórias. De fato, elas se interpenetram, pois a preocupação das políticas de mão-de-obra para o desenvolvimento profissional ao longo da carreira e em meio escolar converge para aspectos importantes de certas políticas de melhoria das escolas. No melhor dos casos, ambas as políticas podem se complementar, uma reforçando a outra. Entretanto, como o nível de seu objeto (o docente e a escola) é diferente, elas podem ser fontes de tensões por suas ênfases diferentes. Por exemplo, políticas de melhoria da escola centradas essencialmente na avaliação do rendimento dos alunos e em sua publicização para os pais, a quem se oferece a possibilidade de transferir sua criança para outra escola com melhor desempenho, em detrimento da escola de desempenho inferior (caso das escolas americanas sujeitas à legislação No Child Left Behind [Nenhuma criança deixada para trás]), tendem fortemente para o lado da pressão e dos estímulos ao rendimento; não confiam muito em professores reflexivos, que desenvolvem ou adaptam modos de agir aptos a garantir o desenvolvimento harmonioso e equilibrado dos alunos. Pode-se pensar que essas abordagens não exigem um docente "profissional", e até mesmo preferem um docente que domine e execute os métodos e as técnicas reputados eficazes e comprovados.

Podem-se analisar essas políticas com a ajuda de categorias como pressão sobre e apoio dos atores, autonomia e controle, prescrição aber- 
A universidade e a formação profissional dos docentes: novos questionamentos

ta ou fechada, confiança e desconfiança para com os docentes, concepção estreita ou ampla da eficácia do ensino, abordagem empírica, analítica ou situacionista interpretativa da prática, profissionalização concebida como um meio ou como um fim etc.

\section{Desafios políticos e socioepistemológicos}

\section{A colocação em tensão e o papel da universidade}

No plano epistemológico, pode-se sustentar que as políticas de desenvolvimento da mão-de-obra docente, inspiradas numa ideologia profissional, privilegiam tanto os saberes como as tarefas, dois aspectos mencionados e interligados em referenciais de competências. Embora nas bases de conhecimentos sobre o ensino e nos referenciais de competência, essa forma de profissionalização pareça se assentar numa concepção mentalista dos saberes que, supostamente, seriam investidos numa prática concreta, singular e contextualizada, ela não deixa de reconhecer a lógica e o peso da ação (é a noção de saberes práticos) que ela deseja racionalizar numa dialética cuja formação, supostamente, se constituiria entre saberes teóricos e saberes práticos. A formação profissional consiste então em pôr os estudantes em contato com esses saberes teóricos e práticos, tanto na universidade como em meio escolar, quer eles tenham a forma de enunciados declarativos, processuais ou condicionais. A prática é dita profissional pelo fato de remeter a esses saberes explícitos, e a padrões ou normas de prática reconhecidos e fundamentados na pesquisa. Esses saberes e essas normas definem a competência.

Os referenciais de competências estão no cerne das políticas de profissionalização da mão-de-obra. No plano epistemológico, pode-se pensar que eles podem compor-se com diferentes epistemologias da prática, assim como a noção de competência pode se apoiar em diferentes concepções da aprendizagem e do ensino, de tipo quer aplicacionista ou socioconstrutivista. Por sinal, existem exemplos de ambos. Assim, pode-se analisar o referencial de competências dos docentes da Grã-Bretanha (Moon, 2004, p. 105-110) como incorporando de maneira claramente prescritiva o conjunto de comportamentos associados à corrente anglo-americana do ensino eficaz e da "instrução direta" (direct instruction); aliás, ele compreende uma base precisa para avaliar 
os comportamentos dos docentes. Do mesmo modo, segundo De Landsheere \& Larens (2001, p. 552), nos "padrōes" (standards) americanos de competências constam saberes e know-how cuja pesquisa processo-produto, inspirada na psicologia behaviorista e neobehaviorista, permitiu formular. Esses autores descrevem esses referenciais do seguinte modo: 1) eles compreenderiam propostas gerais aplicáveis a todos os docentes; 2) insistiriam na aquisição de saberes essenciais e de capacidades (skills) específicas; 3) aplicariam os mesmos "padrōes" (standards) a todos os docentes, e buscariam eliminar as diferenças nas finalidades perseguidas por diversos programas de formação de docentes; e, finalmente, 4) seriam essencialmente centrados no desempenho e nas capacidades práticas, em detrimento do saber teórico ou da reflexividade. Sua análise do contexto político leva-os a concluírem que, nesse caso, se está lidando com componentes de uma política educativa mais ampla, centrada na medição dos desempenhos (bigh stakes assessments), na avaliação dos programas em razão de seus efeitos medidos, e na prestação de contas regular e com conseqüências. Em suma, o referencial de competências serve de quadro para construir "padrōes" (standards) de desempenho e, portanto, contribui para racionalizar a avaliação do desempenho dos docentes em exercício. Tal desenvolvimento está muito presente nos Estados Unidos, onde a ideologia da performatividade prevalece. De fato, mais do que a profissionalização do ensino, o que preocupa no mais alto grau os políticos americanos é a eficácia do ensino, concebida como efeito direto e medida nas aprendizagens dos alunos, ou, dito de outro modo, a profissionalização surge nesse caso como um meio que deve garantir maior eficácia, e não como um fim em si (Lessard, no prelo).

Em contrapartida, pode-se pensar que os referenciais de competências de Genebra (Perrenoud, 1999), do Québec (MEQ, 2001) e da Bélgica francófona se inspiraram no socioconstrutivismo. Nesses casos, embora incorpore conhecimentos, uma competência é definida como se construindo numa relação entre um sujeito e uma situação profissional; apenas tem sentido em razão desses dois pólos - o sujeito que pensa, interpreta e age em situação profissional ou no âmago de um conjunto de situaçōes profissionais, que compreendem tarefas, ações, coerçôes, recursos etc. Desenvolver competências não é tanto aprender comportamentos precisos e específicos - por assim dizer, extirpados tanto da experiência e da trajetória do sujeito como da situação e, as- 
A universidade e a formação profissional dos docentes: novos questionamentos

sim, objetivados e "essencializados" - ou "métodos" (isto é, o acionamento metódico de um procedimento previamente estabelecido), mas antes saber mobilizar e combinar um conjunto de recursos cognitivos e nãocognitivos para levar em conta a complexidade da situação educativa e nela agir de modo finalizado, adaptado e "eficaz". Aí, competência e desempenho distinguem-se, ou, pelo menos, uma não é reduzida ao outro.

Como produto, portanto, um referencial de competências contém um conjunto de enunciados gerais e abstratos, mais ou menos elaborados e especificados. No caso dos referenciais de inspiração socioconstrutivista, ele exige um importante trabalho de interpretação e de apropriação por parte dos que o utilizam e remetem a ele, trabalho determinante na passagem do currículo oficial de formação ao currículo real. Torna-se então indissociável de um projeto de transformação e de inovação. No outro cenário, ele tende a ser o instrumento de um poder de controle e de "padronização", no sentido de normalização, até mesmo de uniformização das práticas. $\mathrm{O}$ primeiro tipo de referencial é mais exigente pois se recusa a fazer do docente um executante e valoriza uma prática na base do julgamento (judgment-based - Polkinghorne, 2004). Ele reconhece plenamente o docente como quem "concebe projetos e dispositivos fora da própria sala de aula, e une assim o backstage (o público) e o frontstage (o privado), para retomar a distinção feita na análise dos serviços. Ele teria, então, mais condiçôes de conceituar seus próprios instrumentos de gestão da urgência e da adaptação a contextos complexos e instáveis" (Barrère, 2003, p. 27). Esse tipo de referencial coloca muito mais desafios importantes em termos de avaliação do que o primeiro.

Por sua vez, as políticas de melhoria das escolas também podem veicular uma visão estreita ou ampla do ensino e do desenvolvimento profissional dos docentes. Para retomarmos a fórmula provocante de Hargreaves (2002), elas podem transformar as escolas em seitas da formação para o desempenho (performance training sects) ou em verdadeiras comunidades discentes. No primeiro caso, tudo estará submetido ao imperativo do êxito dos alunos em testes padronizados, impostos do exterior, e dados básicos da avaliação dos docentes. A formação dos docentes consistirá em fazê-los aprender e dominar modos de agir cuja eficácia foi comprovada pela pesquisa empírica, em reduzir a variância dos ensinamentos de modo que melhor se garantam as aprendizagens básicas dos alunos e em inculcar-lhes uma ética do desempenho e da responsabilidade. No segundo caso, a abordagem é radicalmente diferente: de fato, 
ela privilegia o sujeito individual e coletivo que age em contexto. As práticas, não dissociadas do sujeito e da situação, são construídas pelo sujeito preso numa rede de interaçóes e coerçôes concretas. Neste caso, a formação toma essencialmente a forma do acompanhamento e da co-construção de práticas inovadoras. Ela se preocupa menos com o que os docentes sabem ou devem saber do que com como os docentes aprendem e poderiam aprender de sua prática, e como eles constroem seu saber e sua identidade profissional no âmago de comunidades de prática.

Essa segunda abordagem pode parecer paradoxal, pois, para retomar uma distinção feita por Le Boterf, estamos, nesse nível, num universo de prescrição aberta (por oposição a um universo de prescrição estrita). Assim, embora se saiba o que se deve deixar de fazer (por exemplo, não fazer mais repetência), não se sabe como gerenciar os percursos dos alunos que permanecem em dificuldade no final de um ciclo de aprendizado. Em vários países, os novos programas de ensino, embora prescritivos, deixam uma margem de manobra maior aos docentes e os incitam a inovar, a fazer sua prática evoluir. Em formação dos professores, isso significa que se deve formar novos docentes para situaçōes profissionais em emergência, ainda incertas e poucos estabilizadas. Com efeito, não há prêt-à-porter ou padrôes de prática para os ciclos de aprendizado, a avaliação autêntica, a diferenciação pedagógica, a liberalização (décloisonnement) e novas modalidades de reagrupamento de alunos, a não-repetência, a elevação cultural e a interdisciplinaridade no secundário etc. Essas inovações pedagógicas e didáticas devem ser construídas, experimentadas e modelizadas por equipes de docentes, se possível em colaboração com pesquisadores capazes de capitalizarem as aquisições e de ressaltarem suas dificuldades e seus escolhos, tanto quanto seus sucessos. Assim, os formadores de professores têm a impressão de estar correndo atrás de um objeto chamado a evoluir rapidamente e cujo desenvolvimento ou ritmo de transformação eles não dominam. Muitos se indagam, então, sobre que sentido devem dar ao desenvolvimento de competências para situaçôes profissionais cujo enquadramento ainda é indeterminado, ou até que sentido devem dar mesmo à noção de competência! Alguns adotam estratégias conservadoras e de espera: antes preparar para a profissão "existente" e esperar que a "emergente" se torne mais precisa. Outros, menos numerosos, aproximam-se do campo e participam de pesquisas colaborativas, cujo fruto pode ser rapidamente reinvestido em formação. Seja como for, 
A universidade e a formação profissional dos docentes: novos questionamentos

nesses cenários, a evolução da prática em contexto supõe, por parte dos formadores de professores, uma postura de acompanhantes, muito mais do que a de treinadores ou modelos.

Nossa proposta não é optar por uma dessas orientações, abordagens ou políticas, entre, por exemplo, referenciais de inspiração socioconstrutivista ou mais empírico-analítica, entre uma vontade de "padronizar" a prática pela difusão e imposição de regras de práticas ditas eficazes e comprovadas e uma abordagem mais situacionista e caracterizada por prescriçôes mais abertas, que apostam numa prática reflexiva. Queremos antes insistir na necessidade de colocar todas em tensão. Seria muito estúpido desconsiderar o que "funciona" e dá "resultados", o que não significa que se deva adotar tudo, sempre, sem condição nem adaptação. Em sentido contrário, embora a eficácia seja incontornável, pois um professor reflexivo há de ser eficaz, não se pode reduzir essa eficácia a uma visão estreita da educação e do desenvolvimento dos jovens. Importa tentar conciliar eficácia e reflexividade.

Optar por uma ou pela outra apresenta limites: em um caso pode dar lugar a derivas tecnicistas, a uma linguagem pretensiosa e a prescrições sem sentido, amparadas por uma burocracia controladora e por uma "nooesfera" proliferante, que invoca de modo imperioso demais a autoridade da "ciência" e da "pesquisa" para regular a prática. Em outro pode levar a um enclausuramento no singular, no único, no local, no situacional e, ultimamente, em práticas não-transferíveis, não-exportáveis ou não-generalizáveis. $\mathrm{O}$ primeiro cenário tem uma propensão quase natural e histórica a determinar e fixar o trabalho prescrito e a controlar aqueles que o executam; o segundo procura adequar-se às pessoas, às realidades e aos contextos concretos e movediços da prática, sem, entretanto, ter condição de ser ampliado ao conjunto do grupo profissional. $\mathrm{O}$ primeiro fabrica uma ortodoxia profissional, com o segundo vive-se freqüentemente demais na margem. Em nome da eficácia, o primeiro tende a uniformizar, normalizar e reduzir a variância ou a dispersão das práticas, ao passo que, em nome do pluralismo e do sujeito autor de sua prática, o segundo insiste no desenvolvimento de um estilo pessoal de ensino etc...

Pode-se pensar que toda profissão se desenvolve segundo esses dois grandes pólos e que ambos são sociologicamente necessários. Torna-se então necessário colocá-los em tensão, não deixar o primeiro sufocar o segundo, nem este recusar toda prescrição fechada. A universi- 
dade, lugar onde a dúvida e o questionamento se praticam normalmente, pode ser propícia a essa colocação em tensão, contanto que, ao contrário da Torre de Pisa, ela não penda sempre para o mesmo lado!

Em formação dos professores, não é preciso que todos os formadores compartilhem a mesma epistemologia da prática. O pluralismo é uma garantia de ceticismo perante toda ortodoxia e, independentemente da necessidade de segurança dos estudantes, o desenvolvimento neles de um verdadeiro sentimento de competência passa certamente pela aprendizagem dirigida do ofício, mas também pela construção de uma relação crítica e pragmática para com a regra.

\section{Como lidar com a obrigação de resultados em formação dos professores?}

Ao refletir em torno dos elementos motores da evolução da formação dos docentes nos EstadosUnidos no decorrer dos 50 últimos anos, M. Cochran-Smith (2001), ex-presidente da American Educational Research Association (AERA) (Associação Americana de Pesquisa em Educação), identificou quatro perguntas que, segundo ela, prevaleceram, cada uma por sua vez. Essas indagaçôes não apenas traduzem preocupaçōes de formadores e pesquisadores como permeiam as esferas da política e da prática educativa. De fato, elas vinculam esses três universos de um certo modo, num dado momento, e constituem, por assim dizer, o núcleo duro de uma conversa no âmago da comunidade educativa. Cochran-Smith ressalta insistentemente que sua lista de indagações não é exaustiva nem o fruto de um consenso no cerne da comunidade, e que nenhuma delas foi, de modo algum, definitivamente resolvida, o que explicaria por que passamos de uma à outra. A evolução explica-se antes por uma diversidade de elementos e de fatores, dos quais vários são externos ao campo.

A primeira pergunta, dominante nos anos de 1950 e 1960, teria sido: "Quais os atributos e as qualidades dos bons docentes, daquelas e daqueles que querem tornar-se um bom docente, e dos programas de formação que lhes são destinados?”. Essa questão suscitou numerosas pesquisas sobre as características pessoais (empatia, caráter, integridade etc.) e intelectuais (nível e cultura geral e disciplinar) dos docentes. Essa preocupação afetou os programas de formação dos quais se questionaram o rigor, a exigência, assim como a relação às disciplinas contri- 
A universidade e a formação profissional dos docentes: novos questionamentos

butivas. Transposto na esfera política, ela colocou em xeque o equilíbrio da formação disciplinar e pedagógica, as qualificações acadêmicas dos formadores e pesquisadores em educação, assim como as estruturas universitárias de gestão dos programas de formação.

A segunda pergunta, que prevaleceu do fim dos anos de 1960 a meados dos anos de 1980, formulava-se assim: "Quais as estratégias e os processos de ensino empregados por docentes eficazes, e quais processos de formação têm mais condição de garantir que eles os aprendam?". Esta é a época do desenvolvimento dos estudos processo-produto, que estabelecem correlações entre comportamentos de docentes e a aprendizagem dos alunos, e, segundo Gage (1985), possibilitam considerar seriamente a constituição de uma base científica para o ensino. Em formação dos professores, incorporaram-se a linguagem e os modelos da pesquisa processo-produto e usaram-se as ferramentas dos pesquisadores para avaliar a competência dos novos docentes. Aberturas para procedimentos mais compreensíveis e muito mais aptos a levar em conta o significado construído dos acontecimentos em classe permitiram descentrar-se um pouco da questão dos comportamentos, das estratégias e dos processos "objetivamente" correlatos à eficácia do ensino.

A pergunta dos anos de 1980 e 1990 era a dos saberes: "O que é que os novos docentes e os docentes em exercício devem saber e saber fazer?", e como corolário: "Qual deve ser a base de conhecimento da formação dos docentes?”. No cerne dessa pergunta, está o desafio da profissionalização do ensino e da formação dos professores. Vários pesquisadores propuseram tipologias e categorizaçōes dos saberes profissionais: saberes teóricos e práticos (Perrenoud), saberes pedagógicos e didáticos (pedagogical content knowledge, Shulman), saberes artesanais (craft knowledge, Grimmett), saberes de trabalho (working knowledge, Kennedy; Tardif e Lessard), saberes para ensinar, saberes de ação (Schon), um saber estratégico (Van der Maren) etc... Esse reconhecimento da variedade dos saberes e de suas relaçoos complexas está vinculado a uma preocupação em melhor articular a formação em meios universitário e escolar, de construir parcerias mais sólidas, apoiadas numa cultura um pouco mais comum e partilhada entre os meios universitário e escolar (Lessard, 2002), ao mesmo tempo em que se tentava explicitar e modelizar o saber de experiência, especificamente em obras formalmente voltadas para a constituição de uma base de conhecimentos (handbooks [manuais], enciclopédias, estado dos saberes etc.). 
Mesmo se, segundo Cochran-Smith, as questôes precedentes não foram esgotadas, a pergunta atual, incontornável, é diferente das precedentes. E a dos resultados ou da eficácia. Ela se formula assim: "Como sabermos se e quando os novos docentes e os docentes em exercício sabem e sabem fazer o que devem saber e saber fazer?". O corolário para a formação dos professores é mais ou menos implícito: se esta desenvolver ferramentas que possibilitem diferenciar quais são os docentes com bom desempenho de seus colegas com desempenho mais fraco, será possível rastrear os percursos de algum modo e saber onde, quando, como, por quem e com que custos esses docentes eficazes foram formados.

Essa pergunta tem um vínculo direto com a primeira forma de profissionalização identificada, a da mão-de-obra docente. Se, de fato, um sistema de ação profissional foi instaurado, tal como descrito anteriormente, é porque deve mesmo produzir efeitos positivos. Se a universidade tem o monopólio de uma formação relativamente longa, é porque essa formação é não somente necessária como também benéfica. $\mathrm{O}$ benefício da formação pode ser evidente e incontestável: por exemplo, ninguém coloca em xeque a necessidade, para os médicos, de conhecerem a anatomia do corpo humano, ou de terem uma sólida formação ética, nem, para os docentes, de conhecerem a(s) disciplina(s) que devem ensinar. Dito isto, os efeitos de vários aspectos da formação dos docentes não parecem "evidentes". Existe uma dúvida bastante difundida quanto à necessidade dessa formação e, por extensão, de todo o sistema de atuação profissional. Essa dúvida é às vezes dramatizada pela mídia, quando, por exemplo, $75 \%$ dos estudantes admitidos num programa de formação dos professores quebequenses são reprovados num teste de francês, língua de ensino, ou 59\% dos docentes diplomados e formalmente habilitados pelo Estado do Massachusetts são reprovados num teste de domínio da língua de ensino. Como enfatiza Murray (apud Cochran-Smith, 2001), por mais que se denunciem o teste, seus vieses e suas fraquezas, esse tipo de dramatização deixa os formadores de professores na defensiva, porque não têm à sua disposição dados "duros" e incontestáveis, que demonstrem que seus diplomados dominam as competências a serem ensinadas. A medição dos resultados da formação é, portanto, politicamente incontornável em nome da própria profissionalização.

Ela também é incontornável no contexto atual das políticas de imputabilidade e de prestação de contas que permeiam todos os cam- 
A universidade e a formação profissional dos docentes: novos questionamentos

pos sociais, inclusive a educação. Se, doravante, as escolas e os docentes em exercício devem ser imputáveis por suas ações, então as instituiçôes de formação de professores, assim como toda universidade a serviço da sociedade, devem sê-lo também.

Essa avaliação dos "resultados" da formação é problemática e os formadores de professores devem refletir seriamente a seu respeito. De fato, ela pode tomar diversas formas. Ela pode ser uma questão de testes impostos aos formandos de um programa de formação de professores, testes que mediriam o quanto os futuros docentes sabem do que deveriam saber em termos de conteúdos de ensino, saberes teóricos em educação e contextos de prática. Medir-se-á, então, os formandos em decorrência de padrões (standards) ou patamares de conhecimento predeterminados. E comparar-se-ão as instituições de formação umas com as outras em razão de seus resultados, e elas serão classificadas. A avaliação dos resultados pode também se basear numa amostra de desempenhos dos docentes em situação real, desempenhos que remetem a expectativas explícitas e graduadas ou a tarefas que devem ser dominadas. Ela pode ser concebida num período de tempo mais comprido, para permitir colher dados sobre as aprendizagens dos alunos a quem o professor ensina, e medir sua contribuição, seu efeito, e o valor que agrega à aprendizagem dos alunos. Nesse último caso, associa-se a avaliação do desempenho do docente à medida das aprendizagens de seus alunos. No mundo anglo-saxão, esses modos de avaliação ou suas variantes estão se difundindo cada vez mais. Ao contrário desses três modos de fazer, a avaliação dos resultados pode ser integrada a todas as etapas e ser de algum modo uma dimensão central da formação, esta tendo como objetivo (entre outros) o de desenvolver um profissional do ensino capaz de formar um juízo sobre seu ensino e seus efeitos sobre a aprendizagem dos alunos. Neste caso, o componente auto-avaliador é importante, assim como as marcas e os testemunhos do desenvolvimento das competências (análises de casos, simulaçōes, portfólios, material didático produzido, relatórios de trocas com pais etc.). Nisso, o que importa não é tanto que a formação tenha produzido um docente eficiente, mas antes que tenha desenvolvido no docente uma competência para compreender o que o torna eficiente ou não dentro de tal ou tal situação com tal ou tal grupo de alunos. Procura-se vincular de maneira fecunda uma postura de pesquisa, um saber profissional e uma prática em devir. 
Como vemos, a avaliação dos resultados da formação pode ser apreendida em referência a uma abordagem empírica e comportamental ou a uma abordagem mais reflexiva.

\section{As relações entre a pesquisa e as políticas e práticas educativas - o retorno da "ciência dura"}

$\mathrm{O}$ uso dos dados de pesquisa na avaliação dos resultados questiona o tipo de relação estabelecido com o saber e com a ciência. Há aqui duas indagações, pelo menos, que se devem esclarecer. Uma concerne à ciência e ao que conta como produção científica. A outra diz respeito à relação que temos com a ciência. Quanto à primeira pergunta, não se pode negar que as políticas atuais do Estado avaliador valorizam consideravelmente os instrumentos de medição quantitativos: os indicadores de rendimento do sistema educativo, os testes para medir a aprendizagem dos alunos, os alvos quantitativos para os planos de desenvolvimento das escolas e dos patamares intermediários etc. Uma maior preocupação pelo desempenho traduz-se numa instrumentação mais forte das políticas no plano quantitativo. Isso contamina de algum modo o mundo da pesquisa, facilmente (demais) seduzido pelas verbas importantes que o Estado está disposto a liberar para trabalhos que meçam a eficiência e a eficácia dos docentes, dos programas, dos dispositivos, das ferramentas e das práticas educativas. Da AERA ao secretário da educação americano, passando pela IEA e pelo Banco Mundial, a ciência "dura" volta em força e especificamente em duas de suas formas estabelecidas: os estudos quantitativos longitudinais e multivariados, e os estudos experimentais ou quase-experimentais. Assim, o Banco Mundial informa-nos que de nada adianta acrescentar um ano de formação suplementar aos programas de formação dos docentes africanos, pois isso não produz efeitos sobre as aprendizagens dos alunos e é muito custoso. O secretário da educação americano, por sua parte, estima que se deve acabar com o monopólio das ciências da educação sobre a formação dos professores, uma vez que a pesquisa "séria" mostra que somente o conhecimento disciplinar e o rendimento num teste de comunicação oral são correlatos a um efeito positivo dos docentes sobre a aprendizagem dos alunos (Lessard, no prelo). Do mesmo modo, as análises multivariadas dos dados do Programa Internacional de Avaliação de Estudantes (PISA - Programme for International Student Assessment) confirmam existirem sistemas de educação mais eficientes que 
A universidade e a formação profissional dos docentes: novos questionamentos

outros e ser possível isolar os fatores políticos, institucionais e pedagógicos que os diferenciam uns dos outros.

Não contestaremos esses resultados de pesquisas provavelmente bem conduzidas. Entretanto, é preciso analisar criticamente a construção das problemáticas de pesquisa que levam a produzir esse tipo de relaçóes entre variáveis, e esse tipo de resultados.

Não se trata de criticar ou de denunciar o retorno dos métodos quantitativos após algumas décadas de abertura para as abordagens mais qualitativas, elas próprias associadas ao retorno do ator e do sentido de suas ações, construídas por meio de suas interações imediatas, mas de ressaltar que ele acompanha e sustenta a implementação de novos modos de regulação e de uma vontade de controle dos atores do sistema submetido aos imperativos do desempenho. Ao mesmo tempo, a "ciência" vê-se investida de uma autoridade surpreendente por poderes públicos que escondem suas escolhas de valores atrás de números "incontestáveis". De fato, cabe-lhe cada vez mais a tarefa de decidir os debates entre os modelos pedagógicos, métodos de ensino, dispositivos institucionais de formação dos docentes etc.

A pesquisa pode esclarecer a decisão sobre desafios educativos importantes e até a pesquisa sobre a formação dos docentes deve se desenvolver, inclusive, nas suas dimensōes avaliadoras. A pesquisa avaliadora é útil e a política baseada em "evidências" (evidence-based policy) em formação dos docentes não deve ser banida. Entretanto, a armadilha que comporta deve ser submetida à crítica: ela reduz a aprendizagem ao que se pode medir; a perícia docente, à sua eficácia, concebida como valor agregado; e o valor da formação, ao seu rendimento. Para evitar essa armadilha, é preciso lembrar a posição weberiana da irredutibilidade dos tipos de juízo e reafirmar que toda formação se assenta em escolhas de valores.

Em suma, o conflito dos métodos renasce e opõe mais firmemente que algumas décadas atrás duas concepçôes da qualidade da pesquisa em educação, uma que se apresenta como restritiva e rigorosa, que elimina boa parte da produção científica porque os dados que usa são "moles", subjetivos, em número insuficiente para generalizar o que quer que seja; e a outra que recusa aplicar de maneira "redutora" os critérios retidos pela primeira concepção, e que insiste nas virtudes científicas da diversidade dos métodos e dos níveis de análise. Como esse debate é legítimo, mas não tem saída possível, pode-se pensar que está fadado a 
se renovar incessantemente, embora esteja claro de qual lado pendem, cada vez mais, os poderes do Estado e as organizações internacionais.

Contudo, além do que se considera como ciência, nossa relação com a ciência também deve ser discutida: Será que os resultados da ciência podem se traduzir quase diretamente em regras de conduta para os atores de um dado campo? Em normas de prática imperiosas? A pesquisa pode e deve nos dizer o que fazer para alcançar tal objetivo? Nossa resposta a essa questão é claramente não. A ciência informa uma prática socialmente constituída: ela não a "funda" e nem a regula em sentido estrito. Essas funçôes decorrem de valores e normas, irredutíveis a enunciados científicos e, no melhor dos casos, objetos de deliberação no cerne de uma comunidade de prática.

A distinção proposta por M. Kennedy (1999) entre um papel instrumental e uma contribuição "conceitual" da pesquisa parece muito esclarecedora. No primeiro caso, recorreríamos à pesquisa para obter e aceitar uma resposta precisa a uma pergunta colocada em termos de relaçōes meios-fins: sim ou não, tal dispositivo, tal intervenção, tal modelo produzem tais efeitos (desejados ou inesperados) sobre tal categoria de pessoas dentro de tais condições? Para alguns, a pesquisa médica atual é presentemente a forma mais evoluída desse tipo de pesquisa, que seria responsável pelos grandes avanços terapêuticos das últimas décadas. Deveríamos, portanto, estender esse tipo de pesquisa ao ensino; é a posição defendida por Bissonnette et al. (2005), por meio de sua tipologia da pesquisa que compreende três níveis: 1) a descrição; 2) a verificação em pequena escala; e 3) o estudo em grande escala, em longo prazo ou ambos. Para esses autores, apenas os resultados de pesquisas de nível 3 podem servir de justificativa a decisóes de implantação generalizada de uma inovação pedagógica ou a decisões a respeito dos conteúdos de formação de docentes.

Para outros, esse modelo e esse tipo de papel da pesquisa são inadequados, e até ingênuos, nos campos sociais. De fato, em nome de uma concepção positivista da ciência, objetiva-se e essencializa-se, por assim dizer, comportamentos, métodos e até mesmo modelos de ensino, anulando assim, com a ajuda de métodos quantitativos elaborados e de amostras de grande tamanho, a ação singular do sujeito que age (ao interpretar, traduzir, significar, selecionar, criticar...) em contexto. Entretanto, não se pode dissociar o trabalho, suas ferramentas e seus 
A universidade e a formação profissional dos docentes: novos questionamentos

gestos do sujeito em formação ou do professor em exercício (que se quer "reflexivo").

No segundo caso, a pesquisa tem uma contribuição significativa pela sua contribuição ao clima da opinião que pode fazer evoluir; ela influencia os modos de pensar mais do que fornece direções políticas ou práticas precisas, ao se combinar com outros tipos de saberes que circulam. Para Kennedy, nada nos permite concluir que a pesquisa científica tem qualidades intrínsecas que a tornariam mais eficiente do que outros tipos de saberes para convencer as instâncias políticas e os professores a modificarem suas políticas ou suas práticas. Pensar de outro modo é fazer prova de muita ingenuidade e não tomar conhecimento do que a pesquisa sobre a difusão e o uso do saber nos ensina! Como negar, por exemplo, a dificuldade que muitos docentes têm para aceitar as conclusões da pesquisa sobre os efeitos da repetência? Entretanto, nesse caso, os resultados da pesquisa não poderiam ser mais claros.

Pode-se desejar que os docentes sejam "pesquisadores", que participem em pesquisas como parceiros, ou que abordem sua prática num espírito de pesquisa, ou ainda que façam prova de abertura perante os resultados da pesquisa e suas implicaçōes para sua prática. Insistiremos para que a concebam, primeiro e essencialmente, como um reservatório de leituras possíveis de sua prática, que permite ampliar sua consciência profissional até dimensões desconhecidas ou dificilmente apreendidas do ensino e da aprendizagem, muito mais do que como um método com regras estritas ou um tanque de respostas, soluções ou técnicas a serem aplicadas. A pesquisa há de ser vista como uma ferramenta útil para pensar sua prática, torná-la mais transparente para si e seus colegas, e fazê-la evoluir. É preciso que, na pesquisa, os docentes sejam mais do que pesquisadores patenteados ou consumidores reverenciadores de resultados de pesquisa. Vários motivos fundamentam esse tipo de relação com a pesquisa: primeiro, nos ofícios do humano, em razão da complexidade das situaçôes profissionais e de seu caráter singular, o professor deve inescapavelmente exercer seu juízo; e isso implica que ultrapasse a aplicação de métodos ou de regras, quer se fundamentem ou não na pesquisa; segundo, em educação, a base de conhecimentos existentes não é nem completa, nem objeto de consensos fortes e relativamente estabilizados. Clivagens reais existem e essas oposições são ao mesmo tempo epistemológicas, axiológicas e políticas. É difícil imaginar como tais divergências poderiam fundir-se rapidamente numa abordagem comum do ofício, e ocasionar, na sua esteira, uma forma de enge- 
nharia que supervisione e domine toda e qualquer prática. É melhor contribuir para que os futuros docentes compreendam que o ensino, como qualquer ofício do humano, é atravessado por dilemas, escolhas de valores, apostas e incertezas, do que iludi-los com falsas garantias de uma engenharia científica da aprendizagem.

$\mathrm{Na}$ verdade, parece-nos que a pesquisa pode produzir conhecimentos novos de alcance geral sobre qualquer atividade, mas que nem todas as atividades exigem remontar a esses conhecimentos gerais para determinar a conduta a seguir. Quando o mais freqüente são casos padronizados, as regras particulares que permitem resolvê-los são suficientes e cognitivamente mais econômicas que o recurso a princípios gerais. Em compensação, quando o mais freqüente são casos individualizados, o que é mais particularmente o caso com os ofícios do humano, então é mais pertinente refletir sobre saberes de alto nível para encontrar, atrás da singularidade, princípios que, após raciocínio, permitam escolher uma conduta eficaz. É o que apreenderam Jamous \& Pelloile (1970) com a ajuda de sua relação entre indeterminação e tecnicidade. Esse último termo mede a função que a aplicação direta de regras e modos de agir desempenha na produção do serviço. A indeterminação, pelo contrário, designa a ausência dessas regras imediatas e o recurso ao raciocínio e à criatividade que o profissional desenvolveu na universidade, durante sua formação profissional.

Nos anos por vir, os formadores de docentes têm um papel crucial a desempenhar na construção da relação dos jovens docentes com a ciência e a pesquisa. A pior coisa seria os formadores desenvolverem nos jovens docentes uma relação reverencial e dócil com as ciências humanas e sociais e estes passarem a vê-las como referência última para fundamentar e regular sua prática.

Neste ponto, a universidade pode trazer uma contribuição significativa. Em teoria, ela é o lugar do pluralismo científico, da crítica e da prática da dúvida. Essas características tradicionais da universidade parecem essenciais para se evitar uma visão redutora do ensino e a dominação incontestada de uma ortodoxia profissional.

\section{Conclusão}

Neste texto dedicado à formação profissional para o ensino, tentamos discernir três desafios importantes: a colocação em tensão de duas abordagens da melhoria da prática e das escolas, num contexto em que 
A universidade e a formação profissional dos docentes: novos questionamentos

as políticas do Estado abrangem tanto a universidade como as escolas; a obrigação de resultados em formação que desponta no horizonte; e o retorno em força da "ciência dura" como autoridade para decidir questôes de valores. Com relação a esses desafios, pode-se ser pessimista, sobretudo quando se mora no continente norte-americano e se acompanha a atuação estadunidense no cerne das organizaçōes internacionais. Pode-se temer que a autonomia profissional dos formadores seja abalada e que, como os docentes em exercício, estes formadores sejam submetidos a uma regulação estatal mais estrita e coercitiva. Contudo, ao mesmo tempo, não se pode deixar de reconhecer que, historicamente, a autonomia universitária sempre foi uma questão relativa, vinculada a relações de força. Pode-se pensar também que uma universidade tem mais autonomia que um instituto de educação (école normale) e que ela pode, ao se reivindicar da "esquerda do parlamento da ciência" (Kant), manter certos perigos a distância. Se, na formação de docentes, a universidade não conseguir colocar numa tensão fecunda abordagens plurais da melhoria da prática e das escolas, ter uma resposta sofisticada à obrigação de resultados, nem desenvolver nos docentes uma relação crítica com a ciência, quem conseguirá? Por uma vez, a universidade e as ciências sociais e humanas estão objetivamente aliadas nesse combate.

Nesse espírito, para os formadores de professores universitários, a pergunta central não é mais: Qual a participação das disciplinas que contribuem para a formação dos professores? Nem mesmo: Como formar bons docentes, tais como definidos por um referencial de competências? Mas: Como formar docentes aptos a aprenderem a partir de sua prática, sendo esta submetida a prescrições abertas? Nesse caso, a entrada privilegiada não é a dos saberes, nem mesmo a das tarefas; é a do sujeito confrontado com situações profissionais complexas e parcialmente indeterminadas.

Recebido em outubro de 2005 e aprovado em dezembro 2005.

\section{Referências bibliográficas}

BARRÈRE, A. Travailler à l'école: que font les élèves et les enseignants du secondaire? Rennes: Presses Universitaires, 2003. 
BISSONNNETTE, S.; RICHARD, M.; GAUTHIER, C. Échec scolaire et réforme éducative: quand les solutions proposées deviennent la source du problème. Québec: PUL, 2005.

BOURDONCLE, R.; LESSARD, C. Qu'est-ce qu'une formation professionnelle universitaire? Les caractéristiques spécifiques: programmes, modalités et méthodes de formation. Revue Française de Pédagogie, Paris, n. 142, p. 131-181, janv./mars 2003.

COCHRAN-SMITH, M. Constructing outcomes in teacher education: policy, practice and pitfalls. Education Policy Analysis Archives, v. 9, n. 11, 2001

DARLING-HAMMOND, L. Teacher quality and student achievement: a review of state policy evidence. Education Policy Analysis Archives, v. 8, n. 1 , jan. 2000.

DELANDSHERE, G.; ARENS, S.A. Representations of teaching and standards-based reform: are we closing the debate about teacher education? Teaching and Teacher Education, New York, v. 17, p. 547566, 2001.

EURYDICE. The teaching profession in Europe: profile, trends and concerns. Report 1: Initial training and transition to working life, general lower secondary education. Brussels, 2002a.

EURYDICE. The teaching profession in Europe: profile, trends and concerns. Report II: Supply and demand, general lower secondary education. Brussels, 2002b.

EURYDICE. The teaching profession in Europe: profile, trends and concerns. Report III: Working conditions and pay, general lower secondary education. Brussels, 2003.

GAGE, N.L. Hard gains in the soft sciences: the case of pedagogy. Bloomington: Phi Delta Kappa’s Center on Evaluation, 1985.

GRIMMETT, P.; DAGENAIS, D.; JACQUET, M.; ILIEVA, R. The contrasting discourses in the professional lives of educators in Vancouver, British Columbia; paper presented as part of symposium entitled The Impact of Educational Policy on the Social context of Teachers' work in Canada, at the annual meeting of the American Educational Research Association, Montréal, Quebec, Canada, april 2005. 
A universidade e a formação profissional dos docentes: novos questionamentos

HARGREAVES, A. Teaching in the knowledge society: education in the age of uncertainty. Nova York: Columbia University, 2002.

JAMOUS, H.; PELLOILE, P. Changes in the French University-Hospital System. In: JaCKSON, J.A. (Ed.). Professions and professionalization. London: Cambridge University, 1970. p. 111-152.

KENNEDY, M. Infusing educational decision making with research. In: Cizek, G.J. (sld.). Handbook of educational policy. San Diego: Academic, 1999. p. 53-79.

LABAREE, D.F. Power, knowledge, and the professionalization of teaching: a genealogy of the movement. Harvard Educational Review, Cambridge, Mass., v. 62, n. 2, p. 123-154, 1992.

LESSARD, C. Le groupe Holmes: sa vison de l'enseignement et de la formation à l'enseignement aux Etats-Unis. Politiques d'Éducation et de Formation, v. 5, n. 2, p. 13-26, 2002.

LESSARD, C. Le débat américain sur la certification des enseignants et le piège d'une politique éducative "evidence-based". Revue Française de Pédagogie. (no prelo)

LESSARD, C.; BOURDONCLE. Qu'est-ce qu'une formation professionnelle universitaire?: conceptions de l'université et formation professionnelle. Revue française de Pédagogie, Paris, n. 139, p. 131154, avril/juin 2002.

MOON, R. Les politiques réformistes: transition dans la formation des enseignants en Angleterre. In: TARDIF, M.; LeSSARD, C. La profession d'enseignant aujourd'hui, évolutions, perspectives et enjeux internationaux. Québec: Université Laval, 2004. p. 95-114.

ORGANISATION FOR ECONOMIC COOPERATION AND DEVELOPMENT (OCDE). Staying ahead: in-service training and teacher professional development. Paris: OCDE, 1998.

ORGANISATION FOR ECONOMIC COOPERATION AND DEVELOPMENT (OCDE). Schooling for tomorrow: what schools for the future?. Paris: CERI, OCDE, 2001.

ORGANISATION FOR ECONOMIC COOPERATION AND 
DEVELOPMENT (OCDE). Teachers matter: attracting, developing and retaining effective teachers. Synthesis report. Paris: OCDE, 2005.

ORGANISATION FOR ECONOMIC COOPERATION AND DEVELOPMENT (OCDE). Teachers for tomorrow's schools: analysis of the world education indicators. Paris: OCDE; UNESCO, 2001.

PERRENOUD, P. Dix nouvelles compétences pour enseigner: invitation au voyage. Paris: ESF, 1999.

POLKINGHORNE, D.E. Practice and the human sciences: the case for a judgment-based practice of care. New York: State University of New York, 2004.

QUÉBEC. Ministère de l'Éducacion. La formation à l'enseignement, les orientations, les compétences professionnelles. Québec, 2001. 
